\title{
Cost-effectiveness of Tamoxifen, Aromatase
} Inhibitor, and Switch Therapy (Adjuvant Endocrine Therapy) for Breast Cancer in Hormone Receptor Positive Postmenopausal Women in India

\author{
Dimple Butani' \\ Nidhi Gupta ${ }^{2}$ \\ Gaurav Jyani (D) \\ Pankaj Bahuguna' \\ Rakesh Kapoor ${ }^{3}$ \\ Shankar Prinja (iD) \\ 'Department of Community Medicine \\ and School of Public Health, Postgraduate \\ Institute of Medical Education and \\ Research, Chandigarh, India; \\ ${ }^{2}$ Department of Radiation Oncology, \\ Government Medical College and \\ Hospital, Chandigarh, India; ${ }^{3}$ Department \\ of Radiation Oncology, Postgraduate \\ Institute of Medical Education and \\ Research, Chandigarh, India
}

Background: Breast cancer is the leading cause of cancer among women in India. Treatment with hormone therapy reduces recurrence. We undertook this cost-effectiveness study to ascertain the treatment option offering the best value for money.

Methods: The lifetime costs and health outcomes of using tamoxifen, AI and switch therapy were measured in a cohort of 50-year-old women with HR-positive early stage breast cancer. A Markov model of disease was developed using a societal perspective with a lifetime study horizon. Local, contralateral, and distant recurrence were modelled along with treatment related adverse effects. Primary data collected to obtain estimates of out-of-pocket expenditure (OOPE) and utility weights. Both health system cost and OOPE were included. The future costs and consequences were discounted at 3\%. A probabilistic sensitivity analysis was used.

Results: The lifetime cost of hormone therapy with tamoxifen, AI and switch therapy was to be ₹1,472,037 (I\$ 68,947), ₹1,306,794 (I\$ 61,208) and ₹1,281,811 (I\$ 60,038). The QALYs lived per patient receiving tamoxifen, AI and switch were 13.12, 13.42 and 13.32. tamoxifen was found to be more expensive and less effective. As compared to switch therapy, AI for five years incurred an incremental cost of ₹259,792 (I\$12,168) per QALY gained. At the willingness to pay equals to per capita GDP of India, there is $55 \%$ probability of AI therapy to be cost-effective compared to switch therapy.

Conclusion: In postmenopausal women with HR-positive early-stage breast cancer, switch therapy is recommended for use on the basis of cost-effectiveness.

Keywords: cost-effectiveness, aromatase inhibitor, tamoxifen, endocrine therapy, breast cancer

\section{Background}

Breast cancer is the leading cancer among women in India with 178,361 new cases in 2020 , which accounts for $13.5 \%$ of all cancers in the country. ${ }^{1}$ This number is predicted to double by year $2025 .^{2}$ Since the mean age of diagnosis of breast cancer in India is 50 years, more than half of breast cancer cases are postmenopausal, and more than $50 \%$ of them have a hormone receptor (HR) positive cancer. ${ }^{3}$ Adjuvant endocrine therapy with aromatase inhibitors (AI) for five years reduces 10-year
Department of Community Medicine and School of Public Health, Postgraduate Institute of Medical Education and

Research, Chandigarh, India

Tel +9l 9872871978

Email shankarprinja@gmail.com 
breast cancer mortality by $40 \%$ compared to no endocrine therapy in early stage HR-positive breast cancer.

All clinical guidelines recommend five years of adjuvant endocrine therapy for early stage HR- positive breast cancer. ${ }^{4,5}$ These recommendations are different for premenopausal and postmenopausal females. For postmenopausal females, there is no uniform consensus. The recommendations include, (i) five years of AI, (ii) two-tothree years of tamoxifen followed by AI for up to five years, (iii) AI for two-to-three years followed by tamoxifen for up to 5 years, and (iv) tamoxifen for five years followed by AI. ${ }^{6,7}$ Various studies have shown that AI are superior to tamoxifen in preventing recurrence and improving overall survival. Consequently all the clinical practice guidelines recommend the use of an $\mathrm{AI}$ at some point of time in the adjuvant endocrine treatment of HRpositive postmenopausal women. ${ }^{8}$

Despite the health benefits delivered by adjuvant endocrine therapy, adherence to treatment remains poor, more so in developing countries like India. ${ }^{9}$ Various reasons for noncompliance include the high cost of the drugs, prolonged duration of treatment and the adverse effects associated with the endocrine therapy. ${ }^{10}$ Lack of consensus on the regimen of endocrine therapy combined with the noncompliance among the patients due to high cost merits an economic analysis.

Several cost-effectiveness analyses have evaluated adjuvant endocrine therapy. ${ }^{11-20}$ However, most of them have compared head-to-head monotherapies and have used effectiveness from clinical data with shorter follow-up. Recently, various clinical trials have reported long-term follow-up results. An economic evaluation using clinical parameters from a recently published meta-analysis will help in generating stronger evidence. ${ }^{7}$

Furthermore, the Indian women are diagnosed with breast cancer 10 years earlier than their Western counterparts, hence the impact of treatment on survival, quality of life and lifetime costs can be significantly different. An economic evaluation from an Indian health care perspective will guide towards better clinical decision making. Moreover, a cost-effectiveness analyses would also help generate evidence in the context of such price setting to determine value-based pricing, which would be of use to the National Pharmaceutical Pricing Authority (NPPA) which regulates the price of several anticancer drugs.

We undertook this study to assess the costeffectiveness of adjuvant endocrine therapy, ie we have compared the effects of aromatase inhibitor and switch therapy (tamoxifen for two years followed by AI for the remaining five years) against tamoxifen in the Indian context among postmenopausal women, with HR-positive breast cancer.

\section{Methods}

The analysis was performed from a societal perspective over a lifetime time horizon. ${ }^{21}$ Future costs and health outcomes were discounted at a rate of $3 \%$ per annum considering recently published national guidelines on economic evaluation. ${ }^{22-24}$

\section{Model Structure}

A Markov model was developed for HR-positive postmenopausal women with early stage breast cancer to stimulate their lifetime costs and consequences. Based on the assumption that the average age of postmenopausal women in India is 50 years, women entered the model at start age of 50 years. ${ }^{25}$ The analysis was performed using an eight health state model built in Microsoft Excel $^{\circledR}$. These included: progression free health state (PFS), locoregional recurrence (LR), contralateral breast cancer (CLB), distant metastasis (DM), endometrial cancer, thromboembolic event, death resulting from breast cancer and all-cause mortality. The model was adapted to utilize a yearly cycle based on available literature. ${ }^{17,20,26,27}$ At model entry all patients had a stable progression free disease. During each year cycle, the women faced a probability of transitioning to a more advanced health state, develop adverse events (AEs), die due to breast cancer or die due to other causes. In terms of AEs, tamoxifen causes endometrial cancer and thromboembolism (deep vein thrombosis, DVT; and pulmonary embolism, $\mathrm{PE}$ ), while AI's have been reported to cause increased risk to musculoskeletal effects like osteoporosis and bone fracture. ${ }^{28}$ The effect of each AE was modelled separately with each exclusive health state. (Figure 1)

Outcomes were calculated based on life years (LY) and quality-adjusted life years (QALY). Results are reported as incremental cost (all costs are reported in Indian National Rupee (₹) and International dollar (I\$) using the average conversion of $1 \mathrm{I} \$=21.3$ in 2020) per LY and QALY gained with use of adjuvant hormone therapy. Since hormone therapy has shown to reduce recurrence rates and specifically incidence of contralateral breast, the costs for management of a CLB for each therapy was reported. As per the guidelines for health technology assessment in India and as per WHO recommendations, 


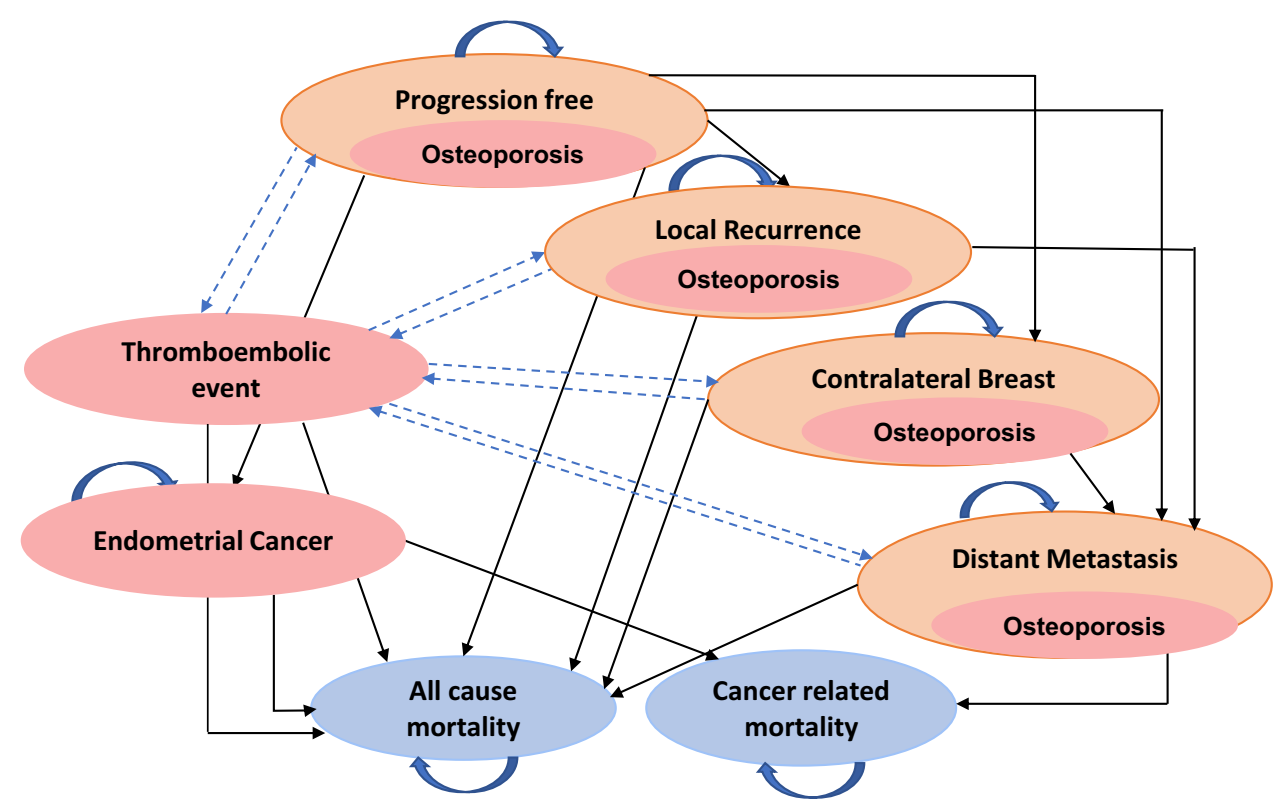

Figure I Markov model depicting the progression of early stage breast cancer patients on adjuvant endocrine therapy.

we used the threshold of per capita gross domestic product (GDP) that equals $₹ 134,400$ (I\$1840) in 2020 to evaluate cost-effectiveness. $^{23,29}$ The International Society for Pharmacoeconomics and Outcomes Research Task Force Consolidated Health Economic Evaluation Reporting Standards (CHEERS) were used to report the findings. ${ }^{30}$

\section{Intervention and Control}

As per the standard guidelines for management of HRpositive breast cancer, adjuvant hormone therapy is administered orally once daily for a minimum duration of five years. We compared three treatment strategies: (i) AI monotherapy (five-years), (ii) tamoxifen monotherapy (five-years), and (iii) switch therapy (tamoxifen for two years followed by AI for up to year five). ${ }^{4,31}$ A notreatment arm was not evaluated in this study because standard guidelines recommend adjuvant endocrine therapy for newly diagnosed HR-positive patients.

\section{Model Assumptions}

We treated the effects for AI drug class as a group without reference to any specific drug. This assumption was based on the fact that adjuvant and neo-adjuvant endocrine therapy studies do not show a significant difference between the three AIs, ie letrozole, anastrozole and exemestane in terms of their effectiveness and adverse effects. ${ }^{6,32}$ Further for simplifying the assessment of costs, the cost of letrozole was taken into account. This assumption was made because letrozole is the most frequently prescribed drug for early breast cancer patients, and the majority of previous studies used letrozole as representative for AI. ${ }^{17,18,27}$

We assumed that patients could experience non-breast cancer death from any health state, but the breast cancer related death occurs only after distant metastasis. Endometrial cancer was modelled as a separate health state and it was assumed that a patient, once diagnosed with endometrial cancer, will stay in that health state or move to death. The occurrence of endometrial cancer is considered to be an extreme adverse effect and it dominates other health states, thus once a patient is diagnosed with this event, the existing treatment with tamoxifen is stopped. Similarly, we modeled thromboembolic events as a separate health state but the event being an acute one, it was modelled as a reversible health state. Since adverse events like endometrial cancer and thromboembolic events (DVT and PE) had long-term implication on quality of life and were associated with elevated risk of dying, ${ }^{33}$ mortality rates due to such events were combined with breast cancer related mortalities. A patient with osteoporosis had a similar risk to move from progression free health state to locoregional recurrence state and so on as a patient without osteoporosis. It was assumed that osteoporosis, once diagnosed, will last for a lifetime. The cost for management of osteoporotic fracture were incorporated separately. 


\section{Valuation of Consequences}

The annual probabilities for breast cancer related events (PFS, LR, CLB, and DM) for year $0-4,5-9$ and $10+$ following treatment initiation were obtained from a recently published meta-analysis reported by EBCTCG. ${ }^{7}$ Table 1 summarizes the model input clinical parameters used in present study. The annual mortality rates for breast cancer related death was obtained by calculating the annual risk of dying from distant metastasis in patients treated with hormone therapy from the same meta-analysis. Risk of death from adjuvant endocrine therapy related adverse events such as endometrial cancer and thromboembolic events were also included. ${ }^{34,35}$ Age-wise risk of mortality as per the Indian sample registration survey life tables was applied to women in all three treatment arms. ${ }^{36}$

To measure the utility weights for a patient in progression-free health state, the EQ-5D instrument, comprising of EQ-5D-5L descriptive system and EQ-VAS was used. The tool was administered to 148 PFS patients visiting a large tertiary hospital. As the tariff values for the EQ5D-5L are not available for India, the EQ-5D-5L health profiles of the patients were converted to their corresponding utility scores using the tariff values from Thailand. ${ }^{37}$ The utility weight for LR, CLB, and DM was obtained from the published result of a meta-analysis on breast cancer related states. ${ }^{38}$ Utility weights for thromboembolic health state, endometrial cancer and osteoporosis were obtained from available literature. ${ }^{39,40}$ An additive method for determining utility scores of patients with comorbid conditions was applied. ${ }^{41,42}$

\section{Costs}

We included both the health-care system cost and out-ofpocket expenditure (OOPE) incurred to patients. Indirect costs such as productivity loss were not considered in view of Indian guidelines for health technology assessment (HTA). Costs were calculated separately considering the distribution of patients in public and private sectors for treatment. ${ }^{43}$ The doses of tamoxifen and letrozole for adjuvant endocrine therapy were $20 \mathrm{mg}$ and $2.5 \mathrm{mg}$ per day, respectively and their daily health system costs were obtained from the procurement rates of medical service corporation in Tamil Nadu. ${ }^{44}$

Health system costs for progression-free health states included the cost of endocrine therapy drug, out-patient consultations (three-monthly for two years, four-monthly for the third year, six-monthly for years four and five, and annually thereafter), annual mammography, annual gynaecological examination for women on tamoxifen, baseline dual-energy X-ray absorptiometry (DEXA) scan for women on AI, with a repeat DEXA scan once in two years. For patients with increased fracture risk, cost of injection zoledronic acid six-monthly, delivered in daycare was included. Costs of calcium and vitamin D supplements were also included for patients on AI. The costs for management of LR, CLB, and DM included the outpatient consultation cost, laboratory tests including hematology, biochemistry, biopsy and receptor status, radiological investigations like mammography, computed tomography, bone scan and PET scan followed by management cost as per disease status that included surgery, chemotherapy, and radiotherapy.

Treatment regimen were followed as per the standard treatment guideline (that included OPD visits, frequency and type of laboratory/diagnostic tests, proportion of patients requiring hospitalization and length of stay) and to keep with real data, we used the rates of various treatment options as reported in the pooled data from Indian cancer registries. ${ }^{31,45-49}$ Similarly, the cost for management of adverse events such as endometrial cancer, thromboembolic event, and osteoporotic fracture were included as per the standard guidelines. ${ }^{50}$ The cost of management of an osteoporotic fracture was calculated using weighted average based on frequency of different sites of fracture in breast cancer patients. ${ }^{6}$ All the costs were determined from either an existing costing study, Costing of Health Services in India (CHSI) ${ }^{51,52}$ or from nationally representative payment rates as listed under the national insurance scheme Ayushman Bharat Pradhan Mantri Jan Arogya Yojana (AB PM-JAY) $)^{53}$ (Table 2).

Out-of-pocket expenditure for patients receiving care from a public tertiary center was calculated separately for each health state. Primary data was collected for PFS from a large tertiary hospital to determine the direct medical and direct nonmedical costs by interviewing 148 patients using a structured questionnaire. The OOPE for patients in LR, CLB, and metastasis was determined deriving direct medical and nonmedical costs for each health state. The direct nonmedical costs for various procedures such as surgery, radiotherapy and chemotherapy were determined from a published Indian study. ${ }^{54}$ The direct medical costs for various chemotherapeutic drugs were obtained by utilizing generic prices. The OOPE for various diagnostic and radiological tests, hormone therapy and other therapeutic drugs were obtained by using market rates or from 


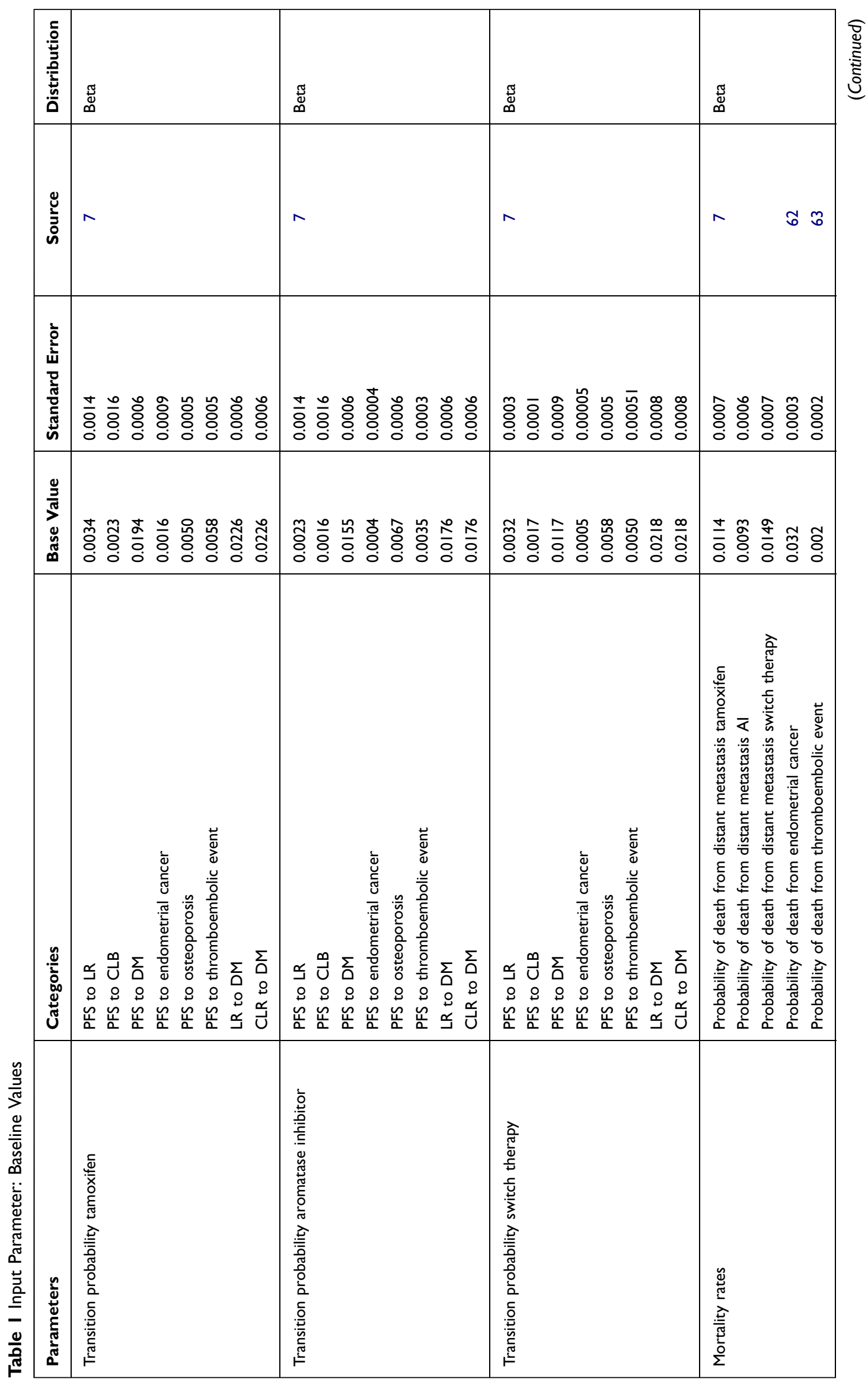




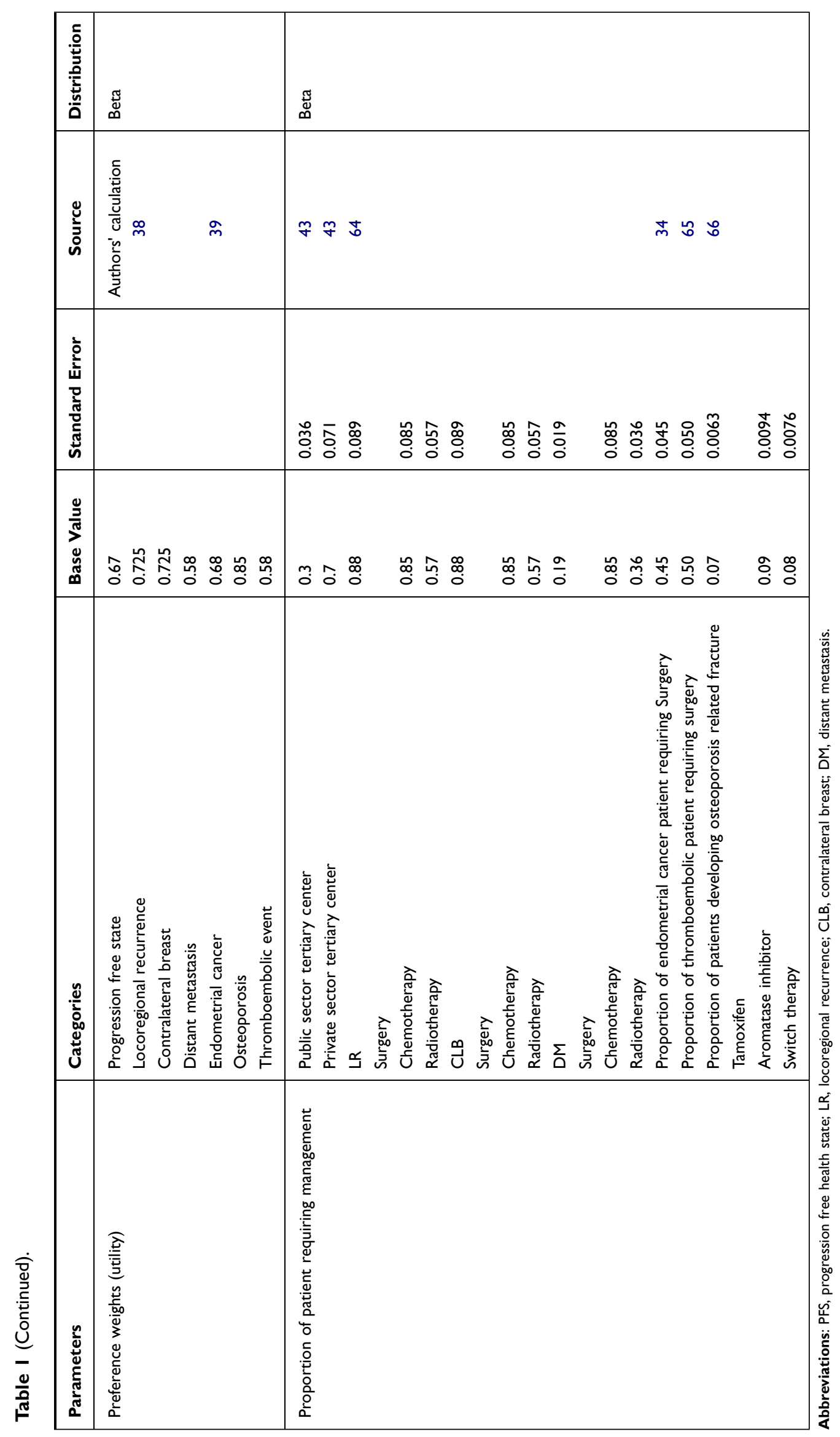


Table 2 Cost Parameters

\begin{tabular}{|c|c|c|c|}
\hline Parameter & Base Value (INR) & 95\%Cl (INR) & Source \\
\hline \multicolumn{4}{|l|}{ I. Drugs } \\
\hline \multicolumn{4}{|l|}{ Health system cost } \\
\hline Annual tamoxifen & 1200 & $600-1800$ & 44 \\
\hline Annual letrozole & 3900 & $1950-5850$ & 44 \\
\hline \multicolumn{4}{|l|}{ OOPE } \\
\hline Annual tamoxifen & 1989 & $995-2984$ & Market rates \\
\hline Annual letrozole & $|I, 57|$ & $5785-17,356$ & Market rates \\
\hline \multicolumn{4}{|l|}{ 2. Procedures } \\
\hline \multicolumn{4}{|l|}{ Health system cost } \\
\hline Radiotherapy & 18,038 & $9018-27,057$ & Authors' calculation \\
\hline Chemotherapy & 13,038 & $6519-19,556$ & Authors' calculation \\
\hline Mastectomy & 20,300 & $20,000-25,000$ & 53 \\
\hline Hysterectomy & 23,000 & $27,000-34,000$ & 53 \\
\hline \multicolumn{4}{|l|}{ OOPE } \\
\hline Radiotherapy & 30,160 & $15,080-45,240$ & 53 \\
\hline Chemotherapy & 14,900 & $7450-22,305$ & 53 \\
\hline Mastectomy & 25,000 & $12,500-37,500$ & Market rates \\
\hline Hysterectomy & 22,000 & $11,000-33,000$ & Market rates \\
\hline \multicolumn{4}{|l|}{ 3. Investigations } \\
\hline \multicolumn{4}{|l|}{ Health system } \\
\hline $\mathrm{CBC}$ & 140 & $70-210$ & 55 \\
\hline DEXA scan & 3834 & $|9| 7-575 \mid$ & 55 \\
\hline Chest X-ray & 4475 & $2238-6713$ & 55 \\
\hline Abdomen USG & 4475 & $2238-6713$ & 55 \\
\hline Breast USG & 300 & $150-450$ & 55 \\
\hline Mammography & 220 & $110-330$ & 55 \\
\hline PET scan & 14,663 & $7332-21,995$ & 55 \\
\hline ECG & 155 & $78-233$ & 55 \\
\hline $\mathrm{ECHO}$ & 258 & $129-387$ & 55 \\
\hline Biopsy & 1107 & $554-166 \mid$ & 55 \\
\hline ER/PR/HER2 & 500 & $250-750$ & 55 \\
\hline \multicolumn{4}{|c|}{ OOPE private sector } \\
\hline $\mathrm{CBC}$ & 377 & $189-566$ & Market rates \\
\hline DEXA scan & 5100 & $2550-7650$ & Market rates \\
\hline Chest X-ray & 400 & $200-600$ & Market rates \\
\hline Abdomen USG & 470 & $235-705$ & Market rates \\
\hline Breast USG & 1840 & $920-2760$ & Market rates \\
\hline Mammography & 2100 & $1050-3150$ & Market rates \\
\hline PET scan & 12,000 & $6000-18,000$ & Market rates \\
\hline ECG & 250 & $125-375$ & Market rates \\
\hline $\mathrm{ECHO}$ & 2400 & $1200-3600$ & Market rates \\
\hline Biopsy & 6000 & $3000-9000$ & Market rates \\
\hline ER/PR/HER2 & 5600 & $2800-8400$ & Market rates \\
\hline
\end{tabular}


Table 2 (Continued).

\begin{tabular}{|l|c|c|c|}
\hline Parameter & Base Value (INR) & 95\%CI (INR) & Source \\
\hline 5. Other & 364 & $214-563$ & 67 \\
\hline Health system & 1671 & $836-2507$ & 67 \\
\hline OPD consultation & \multicolumn{3}{|l|}{} \\
Per day ward charges & 1350 & $675-2025$ & Primary data \\
\hline OOPE & 1800 & $900-2700$ & Authors' calculation \\
\hline OPD consultation & Per day ward charges &
\end{tabular}

Abbreviations: OOPE, out-of-pocket expenditure; CBC, complete blood count; USG, ultrasonography; ECG, electrocardiography; PET, positron emission tomography; ECHO, echocardiogram; ER, estrogen receptor; PR, progesterone receptor; OPD, out patient department; INR, Indian national rupee.

provider payment rates under the national social insurance scheme for central government employees. ${ }^{55}$

The OOPE for patients seeking care in private sector was determined similarly. Costs for hormone therapy, outpatient consultation, diagnostic tests and drugs were obtained by market survey of various online platforms. ${ }^{56,57}$ For determining costs of procedures such as surgery, chemotherapy and radiotherapy package rates as listed in AB PM-JAY were used. ${ }^{53}$ All costs are reported in Indian national rupee (₹) and international dollar (I\$) using the average conversion of $1 \mathrm{I} \$=₹ 21.3$ in 2020.

Table 3 Lifetime Costs, Health Outcomes, and Incremental Values per Patient in Different Treatment Arms: Tamoxifen, Al and Switch Therapy

\begin{tabular}{|c|c|c|c|c|}
\hline \multicolumn{2}{|l|}{ Findings } & \multirow{3}{*}{$\begin{array}{l}\text { Tamoxifen }^{\mathbf{a}} \\
16.74(16.31-17.19) \\
24.49(23.54-25.54)\end{array}$} & \multirow{3}{*}{$\begin{array}{l}\text { Aromatase Inhibitor }^{\mathbf{a}} \\
16.86(16.42-17.26) \\
24.74(23.80-25.73)\end{array}$} & \multirow{3}{*}{$\begin{array}{l}\text { Switch Therapy }^{\mathbf{a}} \\
16.78(16.40-17.14) \\
24.56(23.70-25.43)\end{array}$} \\
\hline LYs & - Discounted & & & \\
\hline & - Undiscounted & & & \\
\hline \multirow[t]{2}{*}{ QALYs } & - Discounted & $13.12(12.19-14.00)$ & $13.42(12.43-14.27)$ & $13.32(12.35-\mid 4.18)$ \\
\hline & - Undiscounted & $18.78(17.23-20.27)$ & $19.34(\mid 7.84-20.7 I)$ & $19.12(|7.65-20.5|)$ \\
\hline \multirow[t]{2}{*}{ Health system cost in million INRs } & - Discounted & $0.78(0.57-1.09)$ & $0.70(0.53-0.94)$ & $0.64(0.46-0.88)$ \\
\hline & - Undiscounted & $1.33(0.95-1.88)$ & $1.16(0.86-1.59)$ & $1.08(0.76-1.52)$ \\
\hline \multirow[t]{2}{*}{ OOPE in million (INR) } & - Discounted & $1.23(1.18-1.25)$ & $1.09(1.01-1.18)$ & $1.08(0.76-1.52)$ \\
\hline & - Undiscounted & $2.05(1.88-2.25)$ & $1.78(1.66-1.89)$ & $1.79(1.65-1.88)$ \\
\hline \multirow[t]{2}{*}{ Total cost in million (INR) } & - Discounted & I.47 (I.64-I.72) & $1.37(1.46-1.52)$ & $1.28(1.44-1.50)$ \\
\hline & - Undiscounted & $2.45(2.72-2.85)$ & $2.13(2.3-2.5)$ & $2.12(2.35-2.50)$ \\
\hline \multicolumn{2}{|l|}{ Incremental values } & Al vs tamoxifen & Switch vs tamoxifen & Al vs switch \\
\hline \multirow[t]{2}{*}{ LYs } & - Discounted & 0.120 & 0.040 & 0.080 \\
\hline & - Undiscounted & 0.251 & 0.067 & 0.183 \\
\hline \multirow[t]{2}{*}{ QALYs } & - Discounted & 0.301 & 0.205 & 0.096 \\
\hline & - Undiscounted & 0.564 & 0.344 & 0.220 \\
\hline \multirow[t]{2}{*}{ Costs in million (INR) } & - Discounted & -0.16 & -0.190 & 0.025 \\
\hline & - Undiscounted & -0.31 & -0.332 & 0.015 \\
\hline
\end{tabular}

Note: ${ }^{a}$ Values in parenthesis represent $95 \%$ confidence intervals.

Abbreviations: LYs, life years; QALYs, quality-adjusted life years; OOPE, out-of-pocket expenditure; INR, Indian national rupee. 
Table 4 Cost of Management of Breast Cancer Recurrence, Contralateral Breast, Adverse Events and Hormone Therapy in Each Treatment Arm: Tamoxifen, Aromatase Inhibitor and Switch Therapy

\begin{tabular}{|c|c|c|c|c|}
\hline \multicolumn{2}{|c|}{ Total Cost per Patient (INR) } & \multirow{2}{*}{$\begin{array}{r}\text { Tamoxifen } \\
\begin{array}{r}|2,06,4| \mid \\
19,99,576\end{array}\end{array}$} & \multirow{2}{*}{$\begin{array}{r}\text { Aromatase Inhibitor } \\
\begin{array}{r}10,89,040 \\
17,54,074\end{array}\end{array}$} & \multirow{2}{*}{$\begin{array}{r}\text { Switch Therapy } \\
10,72,997 \\
17,56,846\end{array}$} \\
\hline Recurrence & $\begin{array}{l}\text { - Discounted } \\
\text { - Undiscounted }\end{array}$ & & & \\
\hline Adverse events & $\begin{array}{l}\text { - Discounted } \\
\text { - Undiscounted }\end{array}$ & $\begin{array}{l}1,32,409 \\
2,33,239\end{array}$ & $\begin{array}{l}1,48,650 \\
2,67,826\end{array}$ & $\begin{array}{l}1,49,500 \\
2,65,831\end{array}$ \\
\hline Contralateral breast & $\begin{array}{l}\text { - Discounted } \\
\text { - Undiscounted }\end{array}$ & $\begin{array}{l}1,33,216 \\
2,21,139\end{array}$ & $\begin{array}{c}69,105 \\
1,|4,7| 4\end{array}$ & $\begin{array}{l}59,315 \\
98,462\end{array}$ \\
\hline Hormone therapy & $\begin{array}{l}\text { - Discounted } \\
\text { - Undiscounted }\end{array}$ & $\begin{array}{l}26,138 \\
43,650\end{array}$ & $\begin{array}{l}57,505 \\
96,034\end{array}$ & $\begin{array}{l}39,400 \\
65,798\end{array}$ \\
\hline
\end{tabular}

\section{Sensitivity Analysis}

A probabilistic sensitivity analysis (PSA) using a secondorder Monte Carlo simulation was undertaken. Probability of adjuvant endocrine therapy to remain cost-effective at a willingness to pay threshold equal to GDP was estimated. The per capita GDP of India in 2020 was $₹ 134,400$ (I\$ 1840). Beta distribution was used to parameterize transition probability and health state utilities because these are binomial parameters that are constructed in the interval from zero to one. Similarly, gamma distribution was used to for cost parameters. Wherever the upper and lower bounds were not provided in the literature, we assumed variation of $20 \%$ for clinical parameters, whereas the values for cost were varied by $50 \%$ each round around the base value. The number of simulations were fixed to 1000. Median was computed along with 2.5th and 97.5 th percentile to estimate $95 \%$ confidence interval. The results of sensitivity analysis are presented in form of a "Cost-effectiveness plane comparing three treatment arms: Tamoxifen, Aromatase inhibitor and Switch therapy for 5 years" and "Cost-Effectiveness Acceptability Curve" respectively.

\section{Results \\ Costs}

The lifetime cost per patient for those treated with tamoxifen, AI five years, and switch therapy were ₹14,72,037 (I $\$ 68,948$ ), ₹13,06,795 (I\$61,208) and ₹12,81,350 (I

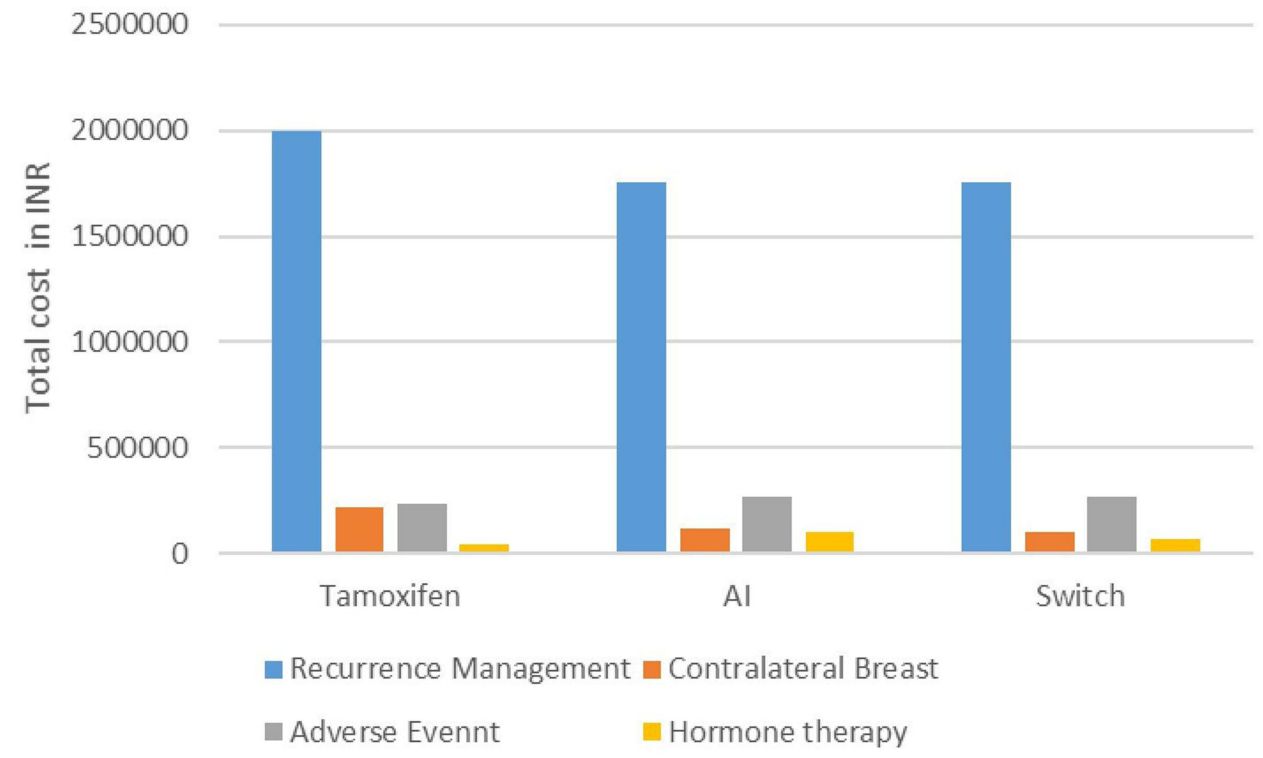

Figure 2 Cost of management of breast cancer recurrence, contralateral breast, adverse events, and hormone therapy in each treatment arm: tamoxifen, aromatase inhibitor, and switch therapy. 


\section{Cost Effectiveness Plane}

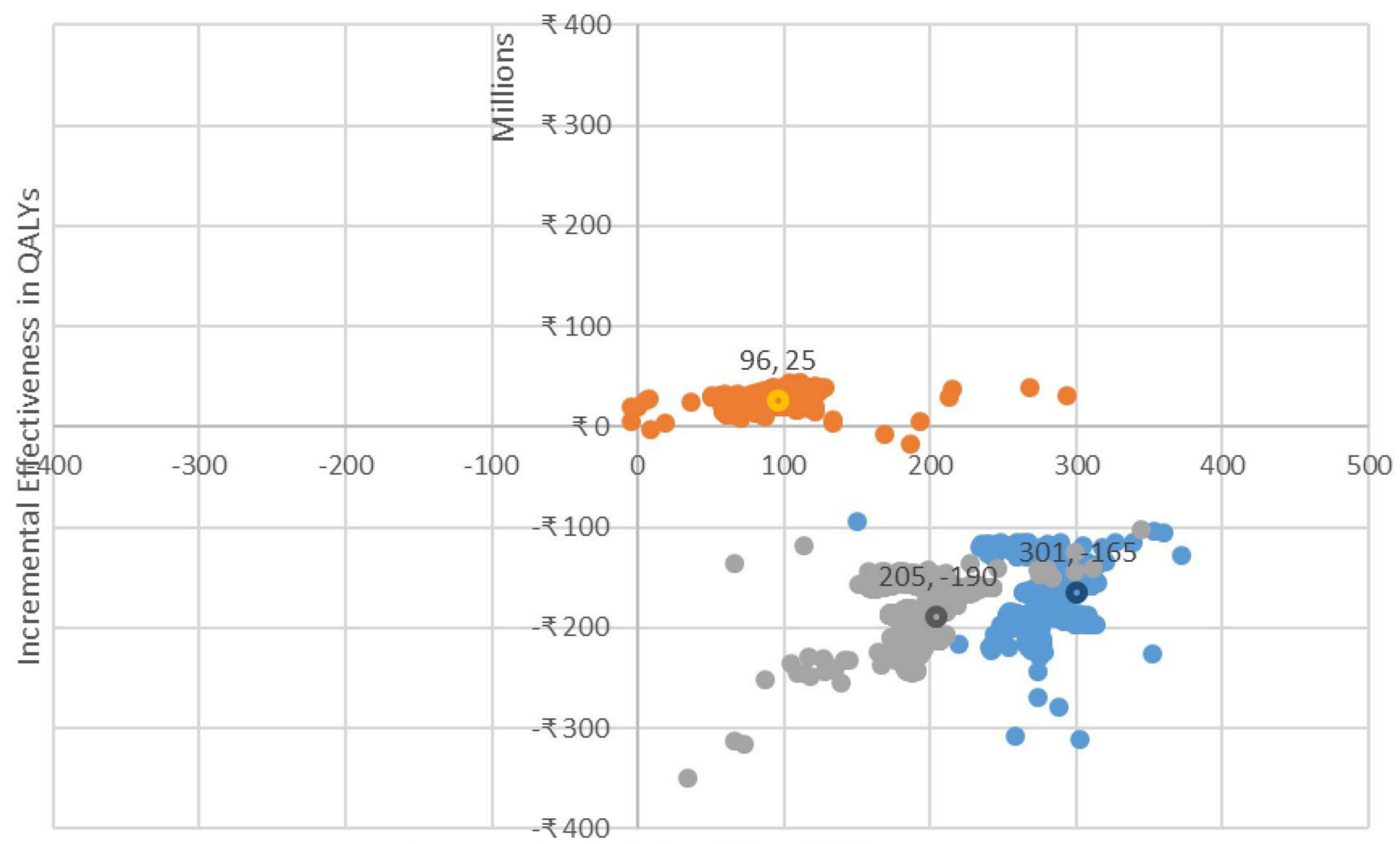

Incremental Costs in millions (INR)

- Al vs Tamoxifen

- Mean ICER
- Al vs Switch

- Mean ICER
- Switch vs Tamoxifen

- Mean ICER

Figure 3 Cost-effectiveness plane comparing three treatment arms: tamoxifen, aromatase inhibitor, and switch therapy for five years.

\section{COST EFFECTIVENESS ACCEPTABILITY CURVE}

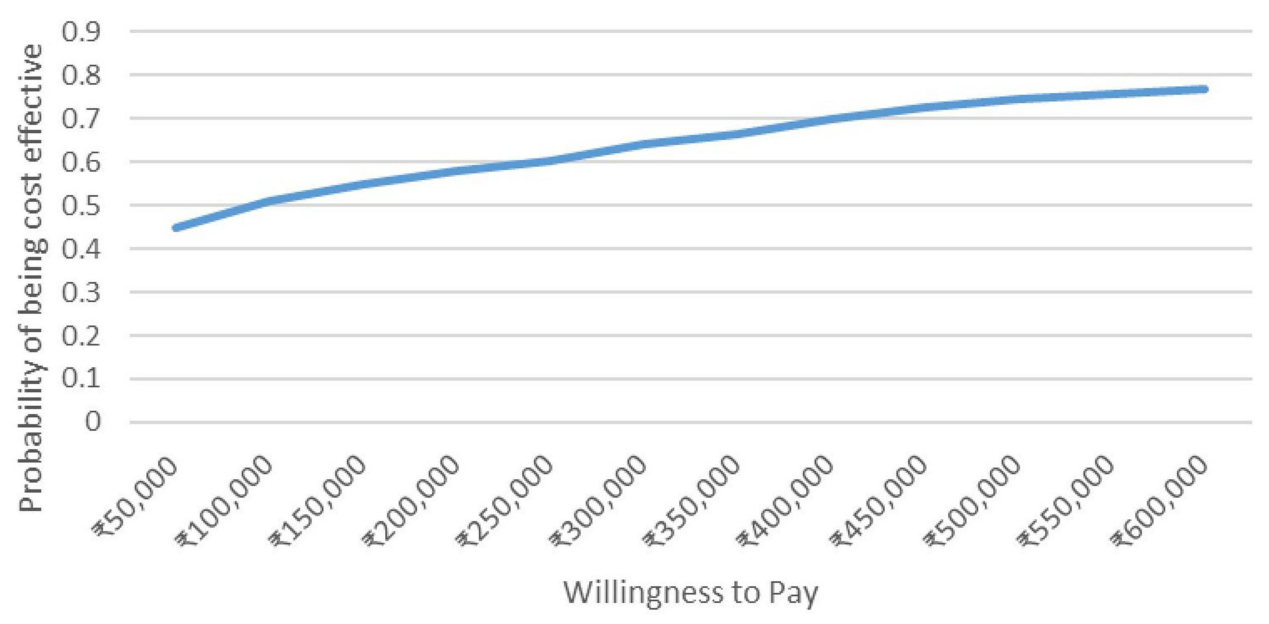

Figure 4 Probability of aromatase inhibitor and switch therapy being cost-effective at varying willingness to pay thresholds. ₹, Indian national rupees. 


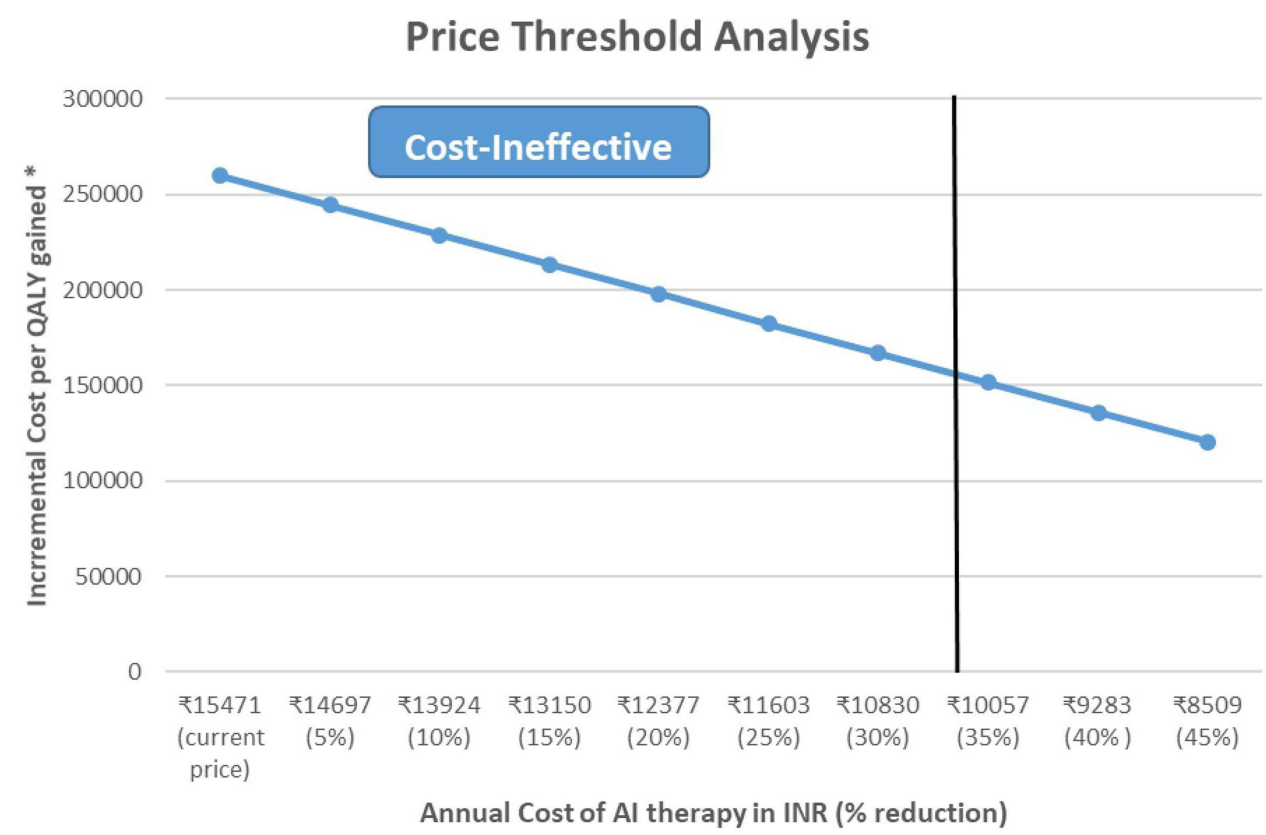

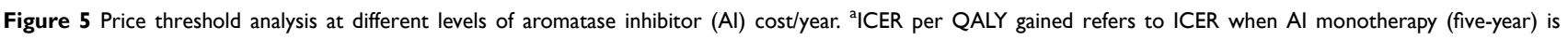
compared with switch therapy.

$\$ 60,016)$, respectively. The incremental cost per patient when tamoxifen was compared with $\mathrm{AI}$ and switch therapy was ₹1,65,242 (I\$7740) and ₹1,90,226 (I\$ 8909), respectively. The incremental cost with AI as compared to switch was ₹24,983 (I\$ 1170) (Table 3).

In the tamoxifen arm, the cost of management of a recurrence, contralateral breast and adverse events per patient was ₹12,06,411 (I\$56,506), ₹1,33,216 (I\$ 6240) and ₹1,32,409 (I\$ 6202) respectively. The five-year cost of tamoxifen drug accounted for ₹26,138 (I\$1,224) per patient (Table 4).

Similarly, the cost for management of a recurrence, contralateral breast and adverse event per patient in case of AI-five years was ₹10,89,040 (I\$51,009), ₹69,105 (I \$3237) and ₹1,48,650 (I\$6962) respectively, and $₹ 10,72,997$ (I\$50,257) ₹59,315 (I\$2778) and ₹1,49,500 (I $\$ 7002$ ) for switch therapy (tamoxifen two years- AI three years), respectively (Figure 2).

The five-year cost of AI-five years and switch therapy was ₹57,505 (I\$2693) and ₹39,400 (I\$1845) per patient.

\section{Health Outcomes}

The number of QALYs lived per patient among those receiving tamoxifen, AI, and switch therapy were 13.11 (12.20-14.00), 13.41 (12.43-14.28) and 13.32 (12.3514.18), respectively. The incremental health benefits of
AI, compared with tamoxifen and switch therapy, were 0.301 and 0.096 QALYs, respectively (Table 3 ).

\section{Cost-effectiveness}

The incremental cost-effectiveness plane comparing the three adjuvant hormone therapies shows that both AI and switch treatment arms are more effective and less costly when compared to tamoxifen. When compared to switch therapy, AI results in incremental cost of ₹2,59,792 (I $\$ 12,168$ ) per QALY gained (Figure 3).

\section{Sensitivity Analysis}

We found that at a willingness to pay equals to per capita GDP of India, there is $55 \%$ probability of AI therapy to be cost-effective compared to switch therapy. (Figure 4). If we reduce the price of AI by $35 \%$ (₹10,057/year) it becomes cost-effective compared with switch therapy at a willingness to pay equal to per capita GDP of India (Figure 5).

\section{Discussion Overview}

The results of our economic evaluation indicate that five years of tamoxifen delivers fewer health benefits and greater lifetime cost when compared to AI monotherapy or switch therapy. The unit cost of tamoxifen is less when 
Table 5 Comparison of Health Outcomes and Cost from Earlier Studies and Present Evaluation

\begin{tabular}{|c|c|c|c|c|}
\hline Study & Outcomes & Tamoxifen & $\begin{array}{l}\text { Aromatase } \\
\text { Inhibitor }\end{array}$ & $\begin{array}{l}\text { Switch } \\
\text { Therapy }\end{array}$ \\
\hline $\begin{array}{l}\text { Economic evaluation of letrozole for early breast cancer in a health } \\
\text { resource limited country (China) })^{18}\end{array}$ & $\begin{array}{c}\text { Costs (CNY } ¥) \\
\text { QALY } \\
\text { Life Years }\end{array}$ & $\begin{array}{l}13,613 \\
10.44 \\
18.34\end{array}$ & $\begin{array}{c}28,797 \\
10.84 \\
19.17\end{array}$ & $\begin{array}{c}20,061 \\
10.7 \mid \\
18.91\end{array}$ \\
\hline $\begin{array}{l}\text { Economic evaluation of hormonal therapies for postmenopausal women } \\
\text { with estrogen receptor-positive early breast cancer in Canada }{ }^{17}\end{array}$ & $\begin{array}{c}\text { Costs (CA\$) } \\
\text { QALYs } \\
\text { Life Years }\end{array}$ & $\begin{array}{c}19,534 \\
8.86 \\
17.93\end{array}$ & $\begin{array}{c}19,359 \\
9.06 \\
18.33\end{array}$ & $\begin{array}{c}18,953 \\
9.05 \\
18.32\end{array}$ \\
\hline Present study & $\begin{array}{c}\text { Costs (INR) } \\
\text { QALYs } \\
\text { Life Years }\end{array}$ & $\begin{array}{c}14,72,037 \\
13.12 \\
16.74\end{array}$ & $\begin{array}{c}13,06,795 \\
13.42 \\
16.86\end{array}$ & $\begin{array}{c}|2,8|, 8|| \\
13.32 \\
16.78\end{array}$ \\
\hline
\end{tabular}

compared to AI, however, due to higher incidence of recurrence rate and contralateral breast cancer with tamoxifen, overall lifetime management costs become higher. In the switch therapy, the incidence of breast cancer events is comparable to the AI arm, but the overall management cost is lower than AI due to low cost of drugs and adverse effect management.

EBCTCG meta-analysis shows that five years of $\mathrm{AI}$ is superior to five years of tamoxifen in decreasing the locoregional recurrence (19\% vs $23 \%$ ) and 10 year mortality $(12 \%$ vs $14 \%$, with the added advantage of decreasing the contralateral breast recurrence. Similarly, when AI is compared with switch therapy the analysis shows that the decrease in locoregional recurrence ( $13.8 \%$ vs $15.5 \%$ ) and decrease in 10 -year mortality ( $8.2 \%$ vs $9.3 \%$ ) is not as significant as seen with tamoxifen. ${ }^{7}$ As a result of these findings, there is no consensus on the best single line of adjuvant hormone therapy in postmenopausal hormone receptor positive patients. Various guidelines recommend five years of tamoxifen or a switch therapy based on informed decisions by physicians about the effectiveness and adverse effect profile. ${ }^{4,31}$

Overall our findings indicate tamoxifen to be costineffective when compared to AI monotherapy and switch therapy. When compared to switch therapy, AI for five years has an incremental cost of ₹259,792 per QALY gained, which is above the threshold for cost-effectiveness in India. Given all parameter uncertainties, switch therapy (tamoxifen for two years followed by AI for three years) is recommended for use in India on grounds of cost-effectiveness.

\section{Model Validation}

When comparing with other cost-effectiveness studies, out of the 15 studies identified for CEA on adjuvant hormone therapies, only two studies compared all the three treatment arms, ie tamoxifen, aromatase inhibitor, and sequential arms. $^{11-20,26,27,58-61}$ The results of present study fall in similar line to these international studies that compared cost- effectiveness of all the three treatment arms available for hormone therapy. Studies done from Canadian and Chinese perspectives have suggested tamoxifen to be the least costeffective option in terms of both cost per life year gained and cost per QALY gained. Our study indicates tamoxifen to be cost-ineffective. When AI-containing strategies were compared (monotherapy and switch), the Canadian study shows results similar to our study, ie they found switch to be the most cost-effective drug when compared to three alternatives. ${ }^{17}$ However, the Chinese study suggested AI therapy to be more effective and less costly. ${ }^{18}$ The results comparing the outcomes with the present study are summarized in (Table 5).

\section{Strengths and Limitations}

The present study is the first economic evaluation of adjuvant hormone therapy for postmenopausal women with hormone receptor positive breast cancer done from an Indian societal perspective. Most of the previous costeffectiveness studies used data from trials such as ATAC, IES, and BIG-1 98. We used clinical data for breast cancer outcomes from the latest updated EBCTCG meta-analysis that presented its results for a mean follow-up period of 10 years. $^{7}$ The results have a higher statistical power and are potentially less biased, thus allowing a generalizability as compared to individual clinical trials results.

Secondly, we used the rates for breast cancer specific events (recurrence, metastasis, breast cancer mortality, etc) for each treatment arm (tamoxifen, AI and switch) separately. We used individual rates for each breast cancer 
event that were time dependent starting from $0-4$ years, 5 9 years and $10+$ years following treatment initiation. Similarly, individual probabilities of adverse events like endometrial cancer were used, which further strengthened the results.

Thirdly, we used primary data of 148 patients on hormone therapy, recruited from two large tertiary care centers in India, to determine the out-of-pocket expenditure and quality of life for progression-free health state of early stage breast cancer patients. Data for cancer costs was obtained from a large nationally representative CHSI study, or from rates listed by India's large-scale health insurance scheme AB-PMJAY and CGHS. Hence our cost results can be generalized to an Indian population. Finally, the cost of management were estimated based on recommended Indian treatment guidelines.

Adverse events have been incorporated with each health state and modelled in way that are similar to real life scenarios.

In spite of our best efforts there are some data limitations our study. A limitation of our study is that the switch involving AI for two-to-three years followed by tamoxifen up to five years was not included in the analysis. However robust clinical data for this arm is not available and hence it could not be included in the analysis. When the local recurrences are compared between starting with AI vs tamoxifen, we see there is a significant decrease in recurrences $(30 \%)$ during the first year of therapy when switch is started with AI and not subsequently. Hence, it would be practical to start the switch with AI and then shift to tamoxifen instead of vice versa.

The cost for treatment of breast cancer was determined based on the recommended standard guidelines by Indian Council of Medical Research. For example, while the cost of radiotherapy was obtained from an original Indian study in the context of head and neck cancer, in our study we used estimates for unit cost of radiotherapy per cycle which is likely to be the same for breast cancer. Since breast cancer is a heterogeneous disease with availability of various treatment options that are personalized based on patient profiles as well as based on ability to pay. However, we believe that our results would be generalizable to the context of a single large payer such as AB-PMJAY. Longer duration of endocrine therapy up to 10 years in high risk cases of hormone receptor positive breast cancer remains a future area of research.

\section{Conclusion and Policy Implications}

Tamoxifen is cost-ineffective compared to the other two treatment options, hence future policy recommendations for treatment guidelines should reconsider the prescription of same to hormone receptor positive postmenopausal women. Based on our study findings, switch therapy is recommended for use on the basis of cost-effectiveness. Reducing the price of aromatase inhibitor by 35\% makes AI-five years the most cost-effective. Future research is required to address uncertainties about long-term breast cancer events and adverse event probabilities.

\section{Abbreviations}

AB-PMJAY, Ayushman Bharat Pradhan Mantri Jan Arogya Yojna; AEs, adverse events; AI, aromatase inhibitor; CHSI, Costing of Health Services in India; CLB, contralateral breast; DEXA, dual-energy X-ray absorptiometry; DM, distant metastasis; DVT, deep vein thrombosis; GDP, gross domestic product; HTA, health technology assessment; INR, Indian national rupee; HR, hormone receptor; LR, local recurrence; LY, life years; NPPA, National Pharmaceutical Pricing Authority; OOPE, out-ofpocket expenditure; PE, pulmonary embolism; PFS, progression-free state; PSA, probabilistic sensitivity analysis; QALY, quality-adjusted life years.

\section{Patient Involvement}

This was conducted in accordance with the Declaration of Helsinki.

\section{Data Sharing Statement}

All data generated or analyzed during this study are included in this published article.

\section{Ethics Approval}

The study protocol was approved by the Institute Ethics Committee of the Post Graduate Institute of Medical Education and Research, Chandigarh, India (NK/6030/ $\mathrm{MPH} / 917)$.

\section{Informed Consent}

Verbal informed consent was obtained as the interviews were conducted by telephone due to COVID-19 surge in country.

\section{Author Contributions}

All authors made a significant contribution to the work reported, whether that is in the conception, study design, execution, acquisition of data, analysis and interpretation, or in all these areas; took part in drafting, revising or critically reviewing the article; gave final approval of the version to be published; have agreed on the journal to 
which the article has been submitted; and agree to be accountable for all aspects of the work.

\section{Funding}

The authors received no specific funding for this work.

\section{Disclosure}

The authors report no conflicts of interest in this work.

\section{References}

1. Sung H, Ferlay J, Siegel RL. Global cancer statistics 2020: GLOBOCAN estimates of incidence and mortality worldwide for 36 cancers in 185 countries. CA Cancer J Clin. 2021;71 (3):209-249. doi:10.3322/CAAC.21660

2. Malvia S, Bagadi SA, Dubey US, Saxena S. Epidemiology of breast cancer in Indian women. Asia Pac J Clin Oncol. 2017;13 (4):289-295. doi:10.1111/AJCO.12661

3. Doval DC, Radhakrishna S, Tripathi Ret al. A multi-institutional real world data study from India of 3453 non-metastatic breast cancer patients undergoing upfront surgery. Sci Rep. 2020;10(1). doi:10.1038/S41598-020-62618-3

4. Lurie RH, Anderson BO, Abraham J, et al. NCCN guidelines version 5.2020 breast cancer; 2020 .

5. Standard treatment guidelines oncology. Ministry of health \& family welfare Government of India 2.

6. Del Mastro L, Mansutti M, Bisagni G, et al. Benefit from letrozole as extended adjuvant therapy after sequential endocrine therapy: a randomized, Phase III study of Gruppo Italiano Mammella (GIM). Am Soc Clin Oncol. 2019;37(15_suppl):504. doi:10.1200/ JCO.2019.37.15_SUPPL.504

7. Early Breast Cancer Trialists' Collaborative Group. Aromatase inhibitors versus tamoxifen in early breast cancer: patient-level meta-analysis of the randomised trials. Lancet. 2015;386 (10001):1341-1352. doi:10.1016/S0140-6736(15)61074-1

8. Burstein HJ, Griggs JJ, Prestrud AA, Temin S. American society of clinical oncology clinical practice guideline update on adjuvant endocrine therapy for women with hormone receptor-positive breast cancer. J Oncol Pract. 2010;6(5):243-246. doi:10.1200/JOP.000082

9. Agarwal G, Ramakant P. Breast cancer care in India: the current scenario and the challenges for the future. Breast Care. 2008;3 (1):21. doi: $10.1159 / 000115288$

10. Farias AJ, Hansen RN, Zeliadt SB, Ornelas IJ, Li CI, Thompson B. The association between out-of-pocket costs and adherence to adjuvant endocrine therapy among newly diagnosed breast cancer patients. Am J Clin Oncol. 2018;41(7):708-715. doi:10.1097/ COC.0000000000000351

11. Sasse AD, Sasse EC. Cost-effectiveness analysis of adjuvant anastrozol in post-menopausal women with breast cancer. Rev Assoc Med Bras. 2009;55(5):535-540. doi:10.1590/S0104-42302009000500015

12. Locker GY, Mansel R, Cella D, Dobrez D, Sorensen S, Gandhi SK. Cost-effectiveness analysis of anastrozole versus tamoxifen as primary adjuvant therapy for postmenopausal women with early breast cancer: a US healthcare system perspective. The 5-year completed treatment analysis of the ATAC ("Arimidex", Tamoxifen Alone. Breast Cancer Res Treat. 2007;106(2):229-238. doi:10.1007/ S10549-006-9483-6

13. Lux MP, Wöckel A, Benedict A, et al. Cost-effectiveness analysis of anastrozole versus tamoxifen in adjuvant therapy for early-stage breast cancer - a health-economic analysis based on the 100-month analysis of the ATAC trial and the German health system. Onkologie. 2010;33(4):155-166. doi:10.1159/000286233
14. Mansel R, Locker G, Fallowfield L, Benedict A, Jones D. Costeffectiveness analysis of anastrozole vs tamoxifen in adjuvant therapy for early stage breast cancer in the United Kingdom: the 5-year completed treatment analysis of the ATAC ('Arimidex', Tamoxifen alone or in combination) trial. Br J Cancer. 2007;97(2):152-161. doi:10.1038/sj.bjc. 6603804

15. Moeremans K, Annemans L. Cost-effectiveness of anastrozole compared to tamoxifen in hormone receptor-positive early breast cancer. Analysis based on the ATAC trial. Int J Gynecol Cancer. 2006;16 (Suppl 2):576-578. doi:10.1111/J.1525-1438.2006.00699.X

16. Fonseca M, Araújo GTB, Saad ED. Cost-effectiveness of anastrozole, in comparison with tamoxifen, in the adjuvant treatment of early breast cancer in Brazil. Rev Assoc Med Bras. 2009;55(4):410-415. doi:10.1590/s0104-42302009000400015

17. Djalalov S, Beca J, Amir E, Krahn M, Trudeau ME, Hoch JS. Economic evaluation of hormonal therapies for postmenopausal women with estrogen receptor-positive early breast cancer in Canada. Curr Oncol. 2015;22(2):84-96. doi:10.3747/CO.22.2120

18. Ye M, Lu J, Yang F, Wu B. Economic evaluation of letrozole for early breast cancer in a health resource-limited setting. Biomed Res Int. 2018;2018:1-8. doi:10.1155/2018/9282646

19. Delea TE, Karnon J, Sofrygin O, Thomas SK, Papo NL, Barghout V. Cost-effectiveness of letrozole versus tamoxifen as initial adjuvant therapy in hormone receptor-positive postmenopausal women with early-stage breast cancer. Clin Breast Cancer. 2007;7(8):608-618. doi:10.3816/CBC.2007.N.018

20. Delea TE, El-Ouagari K, Karnon J, Sofrygin O. Cost-effectiveness of letrozole versus tamoxifen as initial adjuvant therapy in postmenopausal women with hormone-receptor positive early breast cancer from a Canadian perspective. Breast Cancer Res Treat. 2008;108 (3):375-387. doi:10.1007/S10549-007-9607-7

21. Early Breast Cancer Trialists' Collaborative Group. Effects of chemotherapy and hormonal therapy for early breast cancer on recurrence and 15-year survival: an overview of the randomised trials. Lancet. 2005;365(9472):1687-1717. doi:10.1016/S0140-6736(05) 66544-0

22. Prinja S, Chauhan AS, Angell B, Gupta I, Jan S. A systematic review of the state of economic evaluation for health care in India. Appl Health Econ Health Policy. 2015;13(6):595-613. doi:10.1007/ S40258-015-0201-6

23. Department of Health Research, Ministry of Health \& Family Welfare. Health technology assessment in India a manual; 2018. Available from: https://dhr.gov.in/. Accessed July 31, 2021.

24. Tan-Torres Edejer T. Making choices in health: WHO guide to cost-effectiveness analysis; 2003. Available from: https://www.who. int/choice/publications/p_2003_generalised_cea.pdf. Accessed July 31, 2021.

25. Manoharan N, Nair O, Shukla NK, Rath GK. Descriptive epidemiology of female breast cancer in Delhi, India. Asian Pac J Cancer Prev. 2017;18(4):1015-1018. doi:10.22034/APJCP.2017.18.4.1015

26. Rocchi A, Verma S. Anastrozole is cost-effective vs tamoxifen as initial adjuvant therapy in early breast cancer: Canadian perspectives on the ATAC completed-treatment analysis. Support Care Cancer. 2006;14(9):917-927. doi:10.1007/s00520-006-0035-8

27. Shih V, Chan A, Xie F, Ko Y. Economic evaluation of anastrozole versus tamoxifen for early stage breast cancer in Singapore. Value Heal Reg Issues. 2012;1(1):46-53. doi:10.1016/J.VHRI.2012.03.013

28. Amir E, Seruga B, Niraula S, Carlsson L, Ocaña A. Toxicity of adjuvant endocrine therapy in postmenopausal breast cancer patients: a systematic review and meta-analysis. J Natl Cancer Inst. 2011;103 (17):1299-1309. doi:10.1093/JNCI/DJR242

29. World Health Organization. WHO guide to cost-effectiveness analysis. Geneva: World Health Organization. Available from: https://www.who.int/choice/publications/p_2003_generalised_cea. pdf. Accessed October 10, 2021. 
30. Husereau D, Drummond M, Petrou S. Consolidated health economic evaluation reporting standards (CHEERS)-explanation and elaboration: a report of the ISPOR health economic evaluation publication guidelines good reporting practices task force. Value Health. 2013;16 (2):231-250. doi:10.1016/J.JVAL.2013.02.002

31. ICMR. Consensous document for management of breast cancer; 2016. Available from: http://cancerindia.org.in/wp-content/uploads/ 2017/11/Breast_Cancer.pdf. Accessed October 29, 2021.

32. Smith I, Yardley D, Burris Het al. Comparative efficacy and safety of adjuvant letrozole versus anastrozole in postmenopausal patients with hormone receptor-positive, node-positive early breast cancer: final results of the randomized phase III Femara versus Anastrozole Clinical Evaluation (FACE) trial. $J$ Clin Oncol. 2017;35 (10):1041-1048. doi:10.1200/JCO.2016.69.2871

33. Khan UT, Walker AJ, Baig S, Card TR, Kirwan CC, Grainge MJ. Venous thromboembolism and mortality in breast cancer: cohort study with systematic review and meta-analysis. BMC Cancer. 2017;17(1):1-13. doi:10.1186/S12885-017-3719-1

34. Fisher B, Costantino JP, Redmond CK, Fisher ER, Wickerham DL, Cronin WM. Endometrial cancer in tamoxifen-treated breast cancer patients: findings from the National Surgical Adjuvant Breast and Bowel Project (NSABP) B-14. J Natl Cancer Inst. 1994;86 (7):527-537. doi:10.1093/jnci/86.7.527

35. Howell A, Cuzick J, Baum Met al. Results of the ATAC (Arimidex, Tamoxifen, Alone or in Combination) trial after completion of 5 years' adjuvant treatment for breast cancer. Lancet. 2005;365 (9453):60-62. doi:10.1016/S0140-6736(04)17666-6

36. SRS bulletin sample registration system registrar general, India; 2016. Available from: http://www.censusindia.gov.in. Accessed July 31, 2021.

37. Tongsiri S, Cairns J. Estimating population-based values for EQ-5D health states in Thailand. Value Health. 2011;14(8):1142-1145. doi:10.1016/J.JVAL.2011.06.005

38. Peasgood T, Ward SE, Brazier J. Health-state utility values in breast cancer. Expert Rev Pharmacoecon Outcomes Res. 2010;10 (5):553-566. doi:10.1586/ERP.10.65

39. Peasgood T, Herrmann K, Kanis JA, Brazier JE. An updated systematic review of Health State Utility Values for osteoporosis related conditions. Osteoporos Int. 2009;20(6):853-868. doi:10.1007/ S00198-009-0844-Y

40. Mittmann N, Trakas K, Risebrough N, Liu BA. Utility scores for chronic conditions in a community-dwelling population. Pharmacoeconomics. 1999;15(4):369-376. doi:10.2165/00019053199915040-00004

41. Gold MR, Franks P, McCoy KI, Fryback DG. Toward consistency in cost-utility analyses: using national measures to create condition-specific values. Med Care. 1998;36(6):778-792. doi:10.1097/00005650-199806000-00002

42. Ara R, Brazier J. Comparing EQ-5D scores for comorbid health conditions estimated using 5 different methods. Med Care. 2012;50 (5):452-459. doi:10.1097/MLR.0B013E318234A04A

43. Implementation MoSaP. Health in India: NSS 71st Round; 2014. Available from: http://mospi.nic.in/. Accessed October 29, 2021.

44. Tamil Nadu Medical Services Corporation Limited. Essential drug 1 year rate contract details from March 2019; 2019. Available from: https://nmsc.tn.gov.in/user_pages/drugtender.php?drugcat=T18028. Accessed July 31, 2021.

45. White RH, Zhou H, Romano PS. Length of hospital stay for treatment of deep venous thrombosis and the incidence of recurrent thromboembolism. Arch Intern Med. 1998;158(9):1005-1010. doi:10.1001/ARCHINTE.158.9.1005

46. Hansen RN, Pham AT, Boing EAet al. Reduced length of stay and hospitalization costs among inpatient hysterectomy patients with postoperative pain management including IV versus oral Acetaminophen. PLoS One. 2018;13(9). doi:10.1371/JOURNAL. PONE.0203746
47. Colzani E, Clements M, Johansson ALV. Risk of hospitalisation and death due to bone fractures after breast cancer: a registry-based cohort study. Br J Cancer. 2016;115(11):1400-1407. doi:10.1038/ BJC.2016.314

48. Goldhirsch A, Glick JH, Gelber RD, Coates AS, Thürlimann B, Senn HJ. Meeting highlights: international expert consensus on the primary therapy of early breast cancer 2005. Ann Oncol. 2005;16 (10):1569-1583. doi:10.1093/ANNONC/MDI326

49. Munshi A, Gupta S, Yarnold J. Guidelines for locoregional therapy in primary breast cancer in developing countries: the results of an expert panel at the 8th Annual Women's Cancer Initiative - Tata Memorial Hospital (WCI-TMH) Conference. Indian J Med Paediatr Oncol. 2012;33(2):112-122. doi:10.4103/0971-5851.99748

50. Passarello K, Kurian S, Villanueva V. Endometrial cancer: an overview of pathophysiology, management, and care. Semin Oncol Nurs. 2019;35(2):157-165. doi:10.1016/J.SONCN.2019.02.002

51. Prinja S, Brar S, Singh MP, et al. Process evaluation of health system costing - experience from CHSI study in India. PLoS One. 2020;15 (5):e0232873. doi:10.1371/JOURNAL.PONE.0232873

52. Prinja S, Singh MP, Guinness L, Rajsekar K, Bhargava B. Establishing reference costs for the health benefit packages under universal health coverage in India: cost of health services in India (CHSI) protocol. BMJ Open. 2020;10(7):e035170. doi:10.1136/ BMJOPEN-2019-035170

53. National Health Authority, Government of India. Health benefit package $2.0 ; 2020$. Available from: https://pmjay.gov.in/sites/ default/files/2021-06/National-Master-for-Website_0.pdf. Accessed July 31, 2021.

54. Chauhan AS, Prinja S, Ghoshal S, Verma R. Economic burden of head and neck cancer treatment in North India. Asian Pac J Cancer Prev. 2019;20(2):403. doi:10.31557/APJCP.2019.20.2.403

55. Ministry of Health \& Family Welfare, Government of India. Central government health scheme; 2021. Available from: https://cghs.gov.in/ index.php. Accessed July 31, 2021.

56. Dr Lal PathLabs. Diagnostics lab test A-Z list | Medical Tests -Dr Lal PathLabs; 2018. Available from: https://www.lalpathlabs.com/testslist.aspx. Accessed July 31, 2021.

57. Practo. Available from: https://www.practo.com/?utm_source=google \& utm_medium $=$ cpc\&utm_campaign=brand-search-practo-consult\&sem= true\&gclid=Cj0KCQjw6ZOIBhDdARIsAMf8YyFa2sdHZyt7Wwf8Dz 7KoVqQQaZJeQy2ra5UcqiorhxLgVwFEFJJfocaAiJ5EALw_wcB. Accessed July 31, 2021.

58. Karnon J, Delea T, Barghout V. Cost utility analysis of early adjuvant letrozole or anastrozole versus tamoxifen in postmenopausal women with early invasive breast cancer: the UK perspective. Eur $J$ Health Econ. 2008;9(2):171-183. doi:10.1007/S10198-007-0058-1

59. Lazzaro C. Cost-utility analysis of anastrozole versus tamoxifen for adjuvant treatment in postmenopausal women with early breast cancer. PharmacoEconomics. 2007;9:31-43. doi:10.1007/ BF03320568

60. Skedgel C, Rayson D, Dewar R, Younis T. Cost-utility of adjuvant hormone therapies with aromatase inhibitors in post-menopausal women with breast cancer: upfront anastrozole, sequential tamoxifen-exemestane and extended tamoxifen-letrozole. Breast. 2007;16(3):252-261. doi:10.1016/J.BREAST.2006.12.002

61. Gamboa O, Díaz S, Chicaíza L, García M. Análisis de costo-efectividad en Colombia de anastrazol Vs. tamoxifeno como terapia inicial en mujeres con cáncer temprano de mama y receptor hormonal positivo [Cost-benefit analysis of anastrazol and tamoxifen in adjuvant treatment of hormone receptor-positive, post-menopausal breast cancer]. Biomedica. 2010;30(1):46-55. Spanish. doi:10.7705/biomedica.v30i1.152

62. Mahdi H, Han X, Moulton L, Vargas R. Trends in survival of patients with uterine serous carcinoma from 1988 to 2011: a population-based study. Int J Gynecol Cancer. 2017;27(6):1155-1164. doi:10.1097/ IGC.0000000000001007 
63. Parkash R, Wee V, Gardner MJ, et al. The impact of warfarin use on clinical outcomes in atrial fibrillation: a population-based study. Can J Cardiol. 2007;23(6):457. doi:10.1016/S0828-282X(07) 70784-5

64. Consolidated report of hospital based cancer registries: 2012-2014. Available from: https://www.ncdirindia.org/All_Reports/HBCR_ REPORT_2012_2014/index.htm. Accessed July 31, 2021.

65. Mansour S, Alotaibi G, Wu C, McMurtry MS. Trends in admission rates and in-hospital stay for venous thromboembolism. Thromb Res. 2017;156:149-154. doi:10.1016/J.THROMRES.2017.06.012
66. Regan MM, Neven P, Giobbie-Hurder A. Assessment of letrozole and tamoxifen alone and in sequence for postmenopausal women with steroid hormone receptor-positive breast cancer: the BIG 1-98 randomised clinical trial at $8 \cdot 1$ years median follow-up. Lancet Oncol. 2011;12(12):1101-1108. doi:10.1016/S1470-2045(11)70270-4

67. Department of Community Medicine \& School of Public Health, PGIMER Chandigarh. National health system cost database for India. PGISPH.IN; 2021. Available from: https://www.healtheco nomics.pgisph.in/costing_web/. Accessed July 31, 2021.

\section{Publish your work in this journal}

Breast Cancer - Targets and Therapy is an international, peer-reviewed open access journal focusing on breast cancer research, identification of therapeutic targets and the optimal use of preventative and integrated treatment interventions to achieve improved outcomes, enhanced survival and quality of life for the cancer patient.
The manuscript management system is completely online and includes a very quick and fair peer-review system, which is all easy to use. Visit http://www.dovepress.com/testimonials.php to read real quotes from published authors. 